\title{
Partial Hydrogenation of Benzene to Cyclohexene over Ru-Zn/MCM-41
}

\author{
Tongtong Zhang, Zhimiao Wang, Qingqing Zhao, Fang Li, and Wei Xue
}

Hebei Provincial Key Lab of Green Chemical Technology \& High Efficient Energy Saving, School of Chemical Engineering \& Technology, Hebei University of Technology, Tianjin 300130, China

Correspondence should be addressed to Fang Li; lifang@hebut.edu.cn and Wei Xue; weixue@hebut.edu.cn

Received 28 December 2014; Accepted 6 February 2015

Academic Editor: Yongchun Hong

Copyright (C) 2015 Tongtong Zhang et al. This is an open access article distributed under the Creative Commons Attribution License, which permits unrestricted use, distribution, and reproduction in any medium, provided the original work is properly cited.

$\mathrm{Ru}-\mathrm{Zn} / \mathrm{MCM}-41$ catalysts for the partial hydrogenation of benzene with differing $\mathrm{Zn}$ contents were prepared by the incipientwetness impregnation method. The evaluation results indicate that $\mathrm{Zn}$ simultaneously depresses the catalysts activity and cyclohexene selectivity. This can be attributed to the change in the amount of the different hydrogenation sites affected by $\mathrm{Zn}$. The weak hydrogenation sites can promote benzene conversion, and the strong hydrogenation sites, a novel kind of hydrogenation site found on the surface of the catalysts under the influence of $\mathrm{Zn}$, are beneficial for cyclohexene hydrogenation.

\section{Introduction}

Cyclohexene is of great industrial importance as it can be used as intermediate material for producing adipic acid, nylon6 , nylon-66, and other fine chemicals. Owing to its atom economy over the dehydration of cyclohexanol, the partial hydrogenation of benzene to cyclohexene has recently been the focus of much attention [1-35]. Ru has been found to be the most efficient catalyst for this process. To improve cyclohexene selectivity, the addition of a second element to the Ru-based catalyst, such as $\mathrm{Zn}[1,3,6,9,13,21,25$, 29, 30], Co [4, 16], Ce [20], Ba [19], Fe [17], La [2, 5, $9,33], \mathrm{B}[7,8,28,35]$, and $\mathrm{Cu}[24]$, is needed. Among these additives, $\mathrm{Zn}$ is the most popular, and to date the only industrialized production process for cyclohexene via the partial hydrogenation of benzene, developed by Asahi Chemical Industry Co., employs the Ru-Zn catalyst.

Though the use of $\mathrm{Zn}$ in the Ru catalyzed partial hydrogenation of benzene is extensive, its effect has not been fully understood up to now. Hu and Chen [6] have studied the partial hydrogenation of benzene over $\mathrm{Ru}-\mathrm{Zn} / \mathrm{SiO}_{2}$ catalysts. The results of this study showed that the catalysts activity decreased with the increasing Zn content, whilst cyclohexene selectivity increased. Hydrogen temperature programmed desorption $\left(\mathrm{H}_{2}-\mathrm{TPD}\right)$ tests revealed that two kinds of hydrogen, both strongly and weakly bonded on the surface of the $\mathrm{Ru}-\mathrm{Zn} / \mathrm{SiO}_{2}$ catalyst, were formed under the influence of $\mathrm{Zn}$. The catalytic activity could be correlated to the total amount of hydrogen desorption on its surface, and as the amount of the weakly bonded hydrogen increases with $\mathrm{Zn}$ content this might be responsible for the increased cyclohexene selectivity. From the adsorption point of view, Yuan et al. [21] investigated the effect of $\mathrm{Zn}$ on a Ru-based catalyst for the partial hydrogenation of benzene. Density functional theory (DFT) calculations suggested that the chemisorption of benzene and cyclohexene on the catalyst was depressed by Zn, especially for the latter. Undesired deep hydrogenation from cyclohexene to cyclohexane in the middle and late reaction stages was effectively retarded, leading to an improved cyclohexene yield.

It has been shown that the addition of $\mathrm{Zn}$ can increase cyclohexene selectivity and give better results for the partial hydrogenation of benzene. In this study we have demonstrated a different phenomenon for the influence of $\mathrm{Zn}$ on the partial hydrogenation of benzene over Ru/MCM- 41 catalysts.

MCM-41, one of the first developed mesoporous materials [36], has been widely used in catalysis [37, 38], adsorption [39], microreactor [40], and other fields because of its remarkable features, such as well-defined pore shape, narrow distribution of pore size, high surface area $(\sim 700-$ $1500 \mathrm{~m}^{2} \mathrm{~g}^{-1}$ ), and large amount of internal hydroxyl (silanol) groups $(\sim 40-60 \%)$. As for the hydrogenation of benzene, 
MCM-41 is more often used as catalyst support in the reaction to obtain cyclohexane $[41,42]$ and hardly used for the partial hydrogenation of benzene to cyclohexene. This difference could be attributed to its relatively smaller pore size with large specific surface area, which increases the diffusion resistance for the obtained cyclohexene from catalyst surface to bulk phase. Therefore, deep hydrogenation to cyclohexane can easily occur.

In our previous study [30], Ru-Zn/MCM-41 catalysts were prepared for partial hydrogenation of benzene and effect of different $\mathrm{Zn}$ precursors was evaluated. Herein, $\mathrm{Ru}-\mathrm{Zn} / \mathrm{MCM}-41$ catalysts with different $\mathrm{Zn}$ contents were prepared by an incipient-wetness impregnation method. The role of $\mathrm{Zn}$ in the catalysts was discussed by studying the catalytic performance for partial hydrogenation of benzene and catalysts characterization. Interestingly, benzene conversion and cyclohexene selectivity decreased simultaneously with increasing $\mathrm{Zn}$ content, with the characterization results showing the appearance of a novel, strong hydrogenation site with the addition of $\mathrm{Zn}$.

\section{Experimental}

2.1. Catalyst Preparation. First of all, the pure siliceous mesoporous MCM-41, with a BET specific surface area of $743.3 \mathrm{~m}^{2} / \mathrm{g}$ and a total pore volume of $0.77 \mathrm{~cm}^{3} / \mathrm{g}$, was synthesized according to the procedure described in [43]. The Ru-Zn/MCM-41 catalysts were then prepared by an incipient-wetness impregnation method. $\mathrm{RuCl}_{3}$ and $\mathrm{ZnSO}_{4}$ were used as precursors for $\mathrm{Ru}$ and $\mathrm{Zn}$, respectively. They were dissolved into appropriate amount of deionized water and impregnated on MCM-41 support. Within all the catalysts, norminal contents of $\mathrm{Ru}$ were kept constant at $1 \mathrm{wt} \%$. After the impregnation, the catalysts were dried at $353 \mathrm{~K}$ overnight and reduced with $\mathrm{H}_{2}$ at $573 \mathrm{~K}$ for $6 \mathrm{~h}$.

2.2. Catalyst Characterization. X-ray diffraction (XRD) was carried out using a Rigaku D/Max-2500 X-ray diffractometer and $\mathrm{Cu} \mathrm{K}_{\alpha}$ radiation, at $40 \mathrm{kV}$ and $100 \mathrm{~mA}$.

Temperature programmed reduction (TPR) was carried out with a Micromeritics 2920 AutoChem II chemisorption analyzer. $100 \mathrm{mg}$ of catalyst and a $10 \%(\mathrm{v} / \mathrm{v}) \mathrm{H}_{2}$-Ar mixture $\left(50 \mathrm{~cm}^{3}\right.$ (STP) $\left.\mathrm{min}^{-1}\right)$ were used. The sample was preheated to $573 \mathrm{~K}$ under $\operatorname{Ar}\left(50 \mathrm{~cm}^{3}\right.$ (STP) $\left.\mathrm{min}^{-1}\right)$ for $1 \mathrm{~h}$ and subsequently cooled to room temperature. The temperature was then increased under the $\mathrm{H}_{2}$-Ar mixture at $10 \mathrm{~K} \mathrm{~min}^{-1}$ and TPR profiles recorded at temperatures up to $773 \mathrm{~K}$.

The dispersion of $\mathrm{Ru}$ metal was measured by $\mathrm{CO}$ pulse chemisorption method using a Micromeritics 2920 AutoChem II chemisorption analyzer. The stoichiometry of $\mathrm{CO}$ to $\mathrm{Ru}$ was assumed to be 1 . Before CO chemisorption was performed, catalyst samples of approximately $500 \mathrm{mg}$ were rereduced in a quartz reactor with pure $\mathrm{H}_{2}$ $\left(50 \mathrm{~cm}^{3}\right.$ (STP) $\left.\mathrm{min}^{-1}\right)$ for $3 \mathrm{~h}$ at $573 \mathrm{~K}$ and then purged in He flow. The temperature of samples was decreased to $323 \mathrm{~K}$ in He flow. The CO chemisorption was performed by pulse injection of pure $\mathrm{CO}$ gas at $323 \mathrm{~K}$.

Hydrogen temperature programmed desorption $\left(\mathrm{H}_{2}-\right.$ TPD) was carried out also with a Micromeritics 2920
TABLE 1: Catalytic performance of Ru-Zn/MCM-41 catalysts with different contents of $\mathrm{Zn}^{\mathrm{a}}$.

\begin{tabular}{lcccc}
\hline $\begin{array}{l}\text { Zn content } \\
(\text { wt\% })\end{array}$ & $t^{\mathrm{b}}(\mathrm{min})$ & $\begin{array}{c}\text { Conv. } \\
(\%)\end{array}$ & $\begin{array}{r}S_{\mathrm{CHE}}{ }^{\mathrm{b}} \\
(\%)\end{array}$ & $\begin{array}{c}Y_{\mathrm{CHE}}{ }^{\mathrm{b}} \\
(\%)\end{array}$ \\
\hline null & 35.0 & 63.3 & 27.6 & 17.5 \\
0.25 & 35.0 & 23.3 & 15.0 & 3.5 \\
0.64 & 15.0 & 1.8 & 45.6 & 0.82 \\
1.0 & 10.0 & 1.0 & 60.0 & 0.60 \\
\hline
\end{tabular}

${ }^{\mathrm{a}}$ Reaction conditions are the same as those of Figure $1 .{ }^{\mathrm{b}}$ The results are provided at the maximum yield of cyclohexene. Conv.:conversion of benzene; $S_{\mathrm{CHE}}$ : selectivity to cyclohexene; $Y_{\mathrm{CHE}}$ : yield of cyclohexene.

AutoChem II chemisorption analyzer. About $100 \mathrm{mg}$ of sample was preheated to $573 \mathrm{~K}$ under $\mathrm{He}\left(50 \mathrm{~cm}^{3}\right.$ (STP) $\left.\mathrm{min}^{-1}\right)$ for $1 \mathrm{~h}$ and subsequently cooled to $323 \mathrm{~K}$. The sample was then saturated with $\mathrm{H}_{2}$ under a $10 \%(\mathrm{v} / \mathrm{v}) \mathrm{H}_{2}$-Ar mixture $\left(25 \mathrm{~cm}^{3}\right.$ (STP) $\mathrm{min}^{-1}$ ) for $30 \mathrm{~min}$ and then purged with He to remove the physisorbed $\mathrm{H}_{2}$. Finally, the temperature was increased under He atmosphere $\left(50 \mathrm{~cm}^{3}\right.$ (STP) $\left.\mathrm{min}^{-1}\right)$ at $10 \mathrm{~K} \mathrm{~min}^{-1}$ and TPD profiles were recorded at temperatures up to $1073 \mathrm{~K}$.

Transmission electron microscopy (TEM) images were obtained with a FEI TECNGI G ${ }^{2}$ microscope.

2.3. Catalytic Activity Test. The partial hydrogenation of benzene was carried out in a $200 \mathrm{~mL}$ stainless steel autoclave fitted with a magnetic stirrer. In a typical experiment, $30 \mathrm{~mL}$ benzene and $0.48 \mathrm{~g} \mathrm{Ru}-\mathrm{Zn} / \mathrm{MCM}-41$ catalyst with $3.4 \mathrm{~g} \mathrm{ZnSO}_{4} \cdot 7 \mathrm{H}_{2} \mathrm{O}$, the cocatalyst, were introduced into the autoclave, together with $60 \mathrm{~mL} \mathrm{H}_{2} \mathrm{O}$ to act as solvent. The autoclave was sealed and pressurized with $\mathrm{N}_{2}$ for leak testing and then purged by low pressure $\mathrm{H}_{2}$ four times to remove $\mathrm{N}_{2}$ and the temperature adjusted to $403 \mathrm{~K}$. Pressurized $\mathrm{H}_{2}$ (5.5 MPa) was then introduced into the autoclave and reacted with benzene. At the end of the reaction the autoclave was cooled in an ice bath and vented. The catalyst was separated by centrifugation, and the liquid was separated into water and an oil phase.

The reaction products in the oil phase were identified and quantified by capillary gas chromatography using a BAIF SP3420 instrument with a $30 \mathrm{~m} \times 0.25 \mathrm{~mm}$ PEG $20 \mathrm{M}$ column and FID.

\section{Results and Discussion}

The Ru-Zn/MCM-41 catalysts with differing contents of $\mathrm{Zn}$ were evaluated for their activity to partial hydrogenation of benzene and the results are shown in Figure 1 and Table 1. When Ru/MCM-41 was used as catalyst, benzene content decreased gradually and the completely hydrogenated product cyclohexane increased monotonically with reaction time. Regarding cyclohexene content, a maximum was obtained at a certain reaction time, exhibiting the well-known behavior of consecutive reactions. The maximum cyclohexene yield was $17.5 \%$ with $62.3 \%$ benzene conversion at 35 min over $\mathrm{Ru} / \mathrm{MCM}-41$ catalyst. When $0.25 \mathrm{wt} \% \mathrm{Zn}$ was introduced into the catalyst, hydrogenation rate decreased obviously. This 


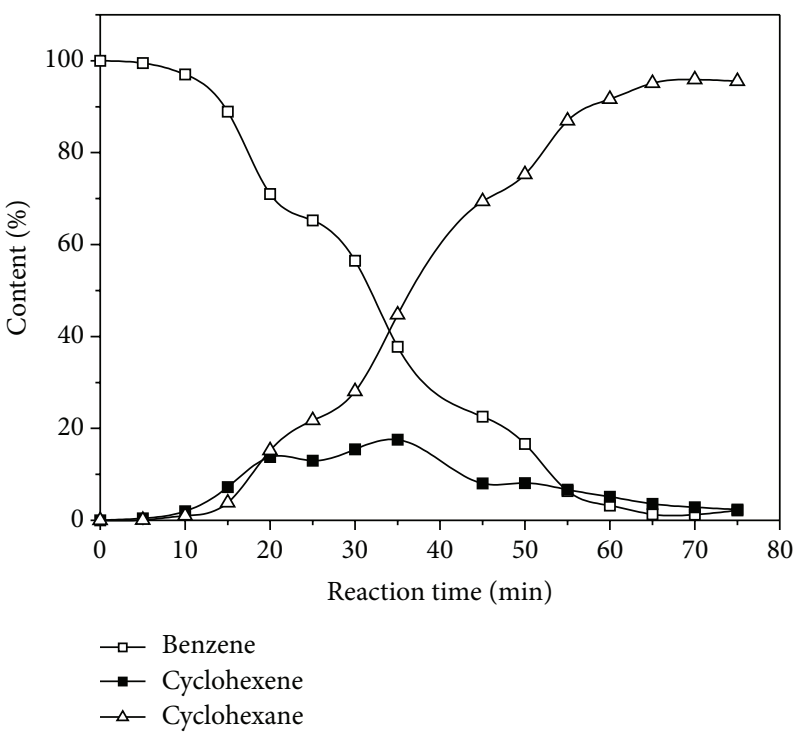

(a)

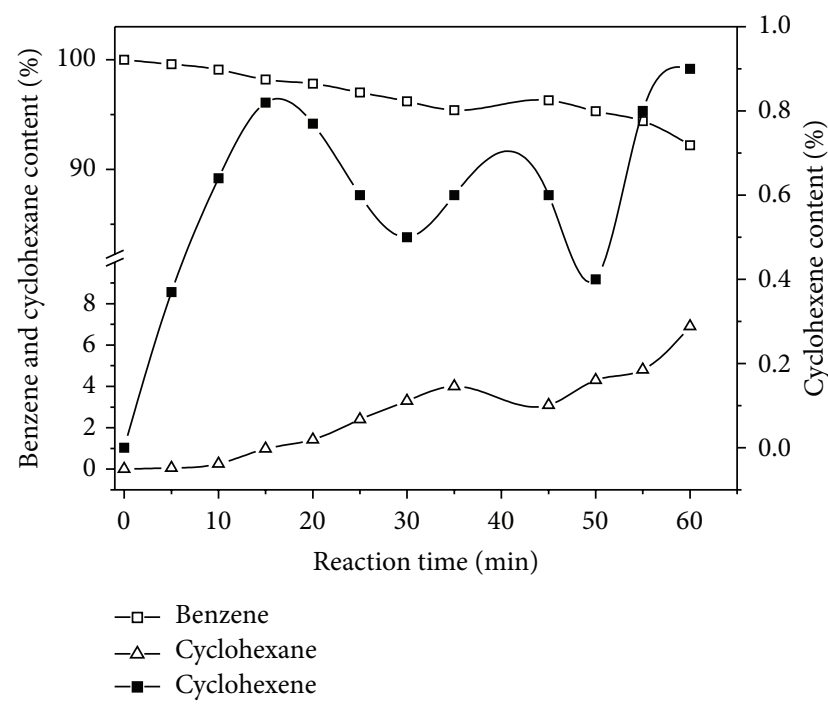

(c)

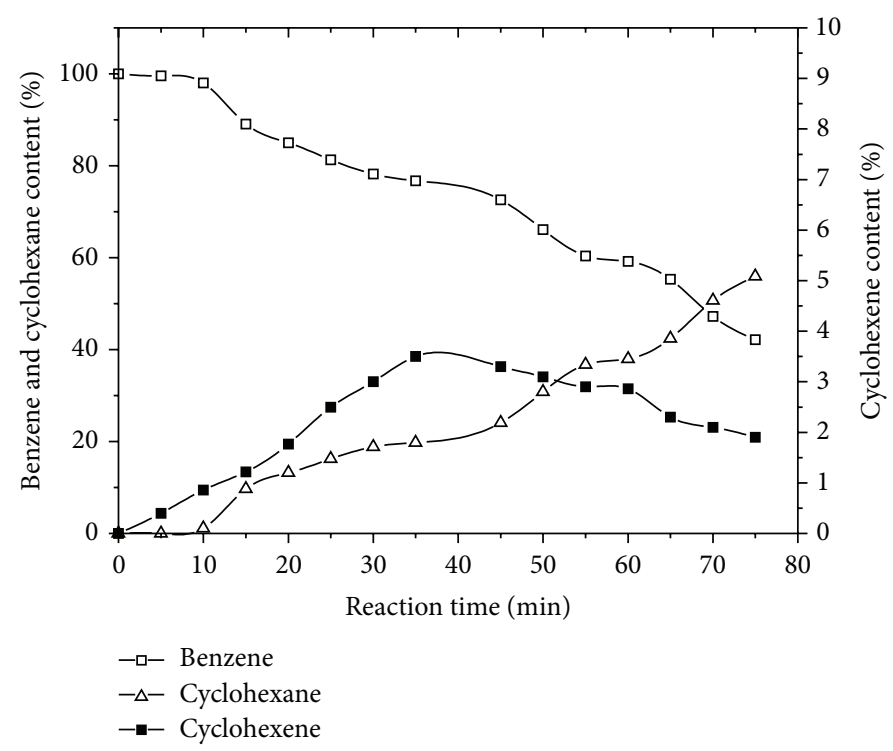

(b)

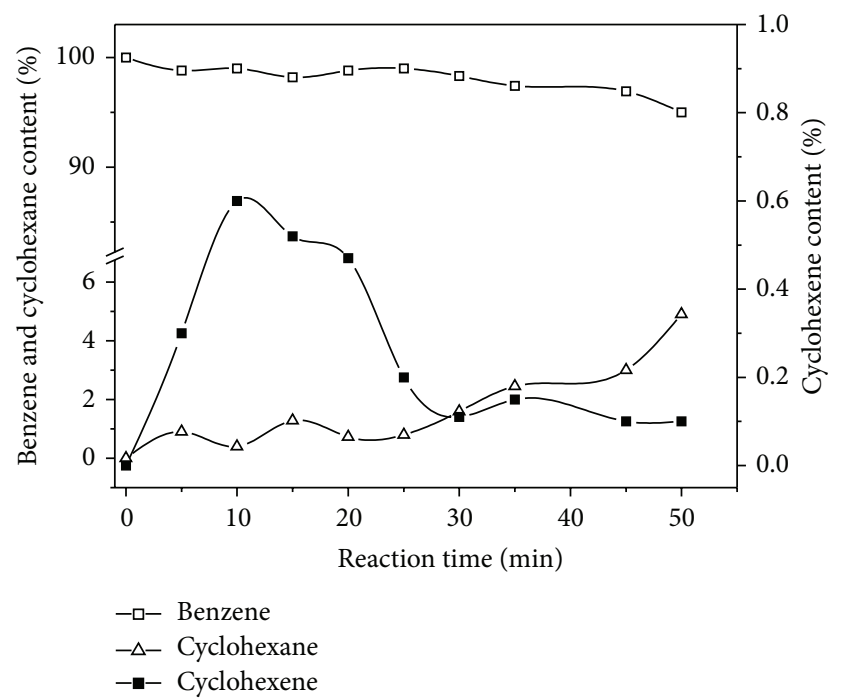

(d)

FIGURE 1: Partial hydrogenation of benzene over Ru-Zn/MCM-41 with different contents of Zn. Zn content: (a) null; (b) 0.25 wt $\%$; (c) 0.64 wt\%; (d) $1 \mathrm{wt} \%$. Reaction conditions: benzene $30 \mathrm{~mL}(0.338 \mathrm{~mol})$, Ru-based catalyst $0.48 \mathrm{~g}\left(\mathrm{Ru} 4.7 \times 10^{-5} \mathrm{~mol}\right), 3.4 \mathrm{~g} \mathrm{ZnSO} \cdot 7 \mathrm{H}_{2} \mathrm{O}$ in $60 \mathrm{~mL} \mathrm{H} \mathrm{H}_{2} \mathrm{O}$, $\mathrm{H}_{2} 5.5 \mathrm{MPa}$, and $403 \mathrm{~K}$.

is in accordance with the other results previously obtained using other Ru-based catalysts [6, 21]. However, in contrast to the usual assumption the cyclohexene content significantly decreased likewise. Most of benzene was hydrogenated completely to cyclohexane. The maximum cyclohexene yield was only $3.5 \%$ with $23.3 \%$ benzene conversion over $\mathrm{Ru}-\mathrm{Zn} / \mathrm{MCM}$ 41 catalyst with $0.25 \mathrm{wt} \% \mathrm{Zn}$. With increasing $\mathrm{Zn}$ content the catalyst activity reduces further. A $1 \mathrm{wt} \%$ of $\mathrm{Zn}$ content gave a maximum cyclohexene yield of $0.6 \%$ with $1.0 \%$ benzene conversion. That is to say, the catalyst lost almost all of its hydrogenation activity under these conditions. And the high cyclohexene selectivity over Ru-Zn/MCM- 41 catalysts with high $\mathrm{Zn}$ content may be the results of ultralow hydrogenation activity.
Characterizations were carried out to understand the influence of $\mathrm{Zn}$ on the $\mathrm{Ru} / \mathrm{MCM}-41$ catalysts. Figure 2(a) shows the small-angle XRD pattern of $\mathrm{Ru}-\mathrm{Zn} / \mathrm{MCM}-41$ catalyst in $1: 1$ ratio. The sample gave a well-defined hexagonal XRD pattern with a main peak at $2^{\circ}$ and up to three signals in the region $3-8^{\circ}$. Figure $2(\mathrm{~b})$ shows the wide-angle XRD patterns of Ru-Zn/MCM-41 catalysts with differing contents of $\mathrm{Zn}$. There is no diffraction peak corresponding to the crystalline compound in the patterns of all samples, which suggested that $\mathrm{Ru}$ and $\mathrm{Zn}$ compounds were highly dispersed in the catalysts.

To investigate the effect of $\mathrm{Zn}$ on the reducibility of $\mathrm{Ru}$ species over MCM-41, $\mathrm{H}_{2}$-TPR measurements of the $\mathrm{Ru}-\mathrm{Zn} / \mathrm{MCM}-41$ catalysts with differing $\mathrm{Zn}$ contents, before 


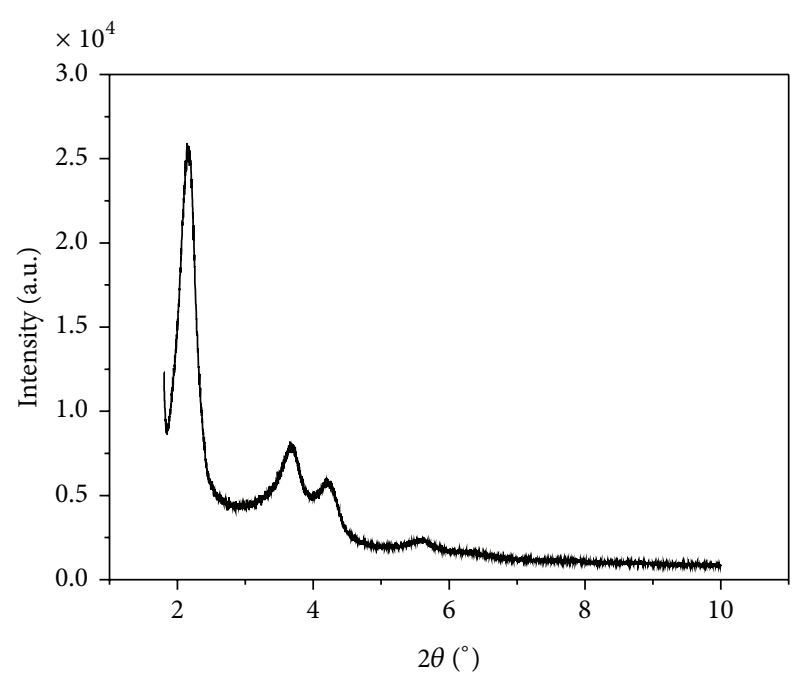

(a)

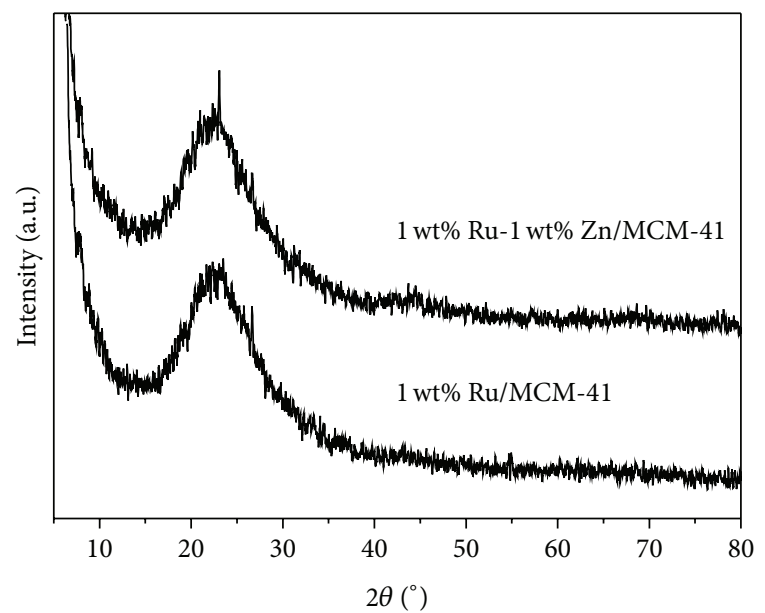

(b)

FIGURE 2: XRD patterns of Ru-Zn/MCM-41 catalysts: (a) small angle XRD; (b) wide angle XRD.

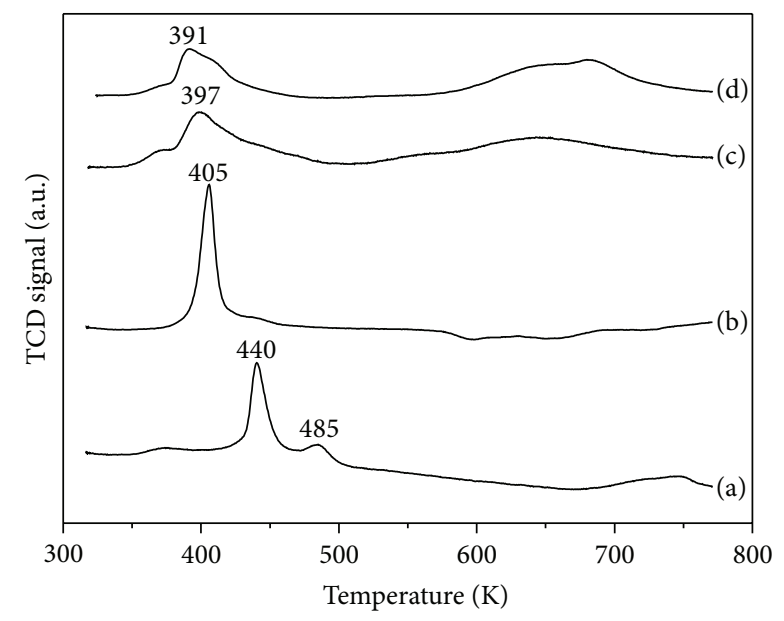

FIGURE 3: TPR profiles of Ru-Zn/MCM-41 catalysts. Zn contents: (a) null; (b) $0.25 \mathrm{wt} \%$; (c) $0.64 \mathrm{wt} \%$; (d) $1 \mathrm{wt} \%$.

reduction by hydrogen, were carried out. The profiles are shown in Figure 3.

The TPR profile of Ru/MCM-41 catalyst (Figure 3(a)) shows a peak with maximum $\left(T_{m}\right)$ at about $440 \mathrm{~K}$, which is related to $\mathrm{RuCl}_{3}$ reduction in the preparation method. However, this peak is a little beyond the range reported for the complete reduction of unsupported $\mathrm{RuCl}_{3}(433 \mathrm{~K},[44])$. This difference could be due to the interaction between $\mathrm{RuCl}_{3}$ and MCM-41 support. Zonetti et al. [14] found two peaks in the TPR profile of $\mathrm{Ru} / \mathrm{CeO}_{2}$, a principal peak at $453 \mathrm{~K}$ with a shoulder around $423 \mathrm{~K}$. They considered the peak at lower temperature corresponding to the reduction of $\mathrm{RuCl}_{3}$ weakly interacting with $\mathrm{CeO}_{2}$ and the peak at higher temperature relating to $\mathrm{RuCl}_{3}$ reduction strongly interacting with the support. There is still a weak peak at $485 \mathrm{~K}$ in the TPR profile of $\mathrm{Ru} / \mathrm{MCM}-41$, which can be assigned to the reduction of
$\mathrm{RuO}_{x}$. It has been found that $\mathrm{RuCl}_{3}$ can be oxidized at the surface by exposure to air at room temperature [45].

With the addition of $\mathrm{Zn}$, the reduction peaks changed significantly as observed in Figure 3. Starting with $0.25 \mathrm{wt} \%$ $\mathrm{Zn}$ content the two reduction peaks resolved into one at about $405 \mathrm{~K}$. With each further addition of $\mathrm{Zn}, T_{m}$ decreased slightly down to $391 \mathrm{~K}$ for $1 \mathrm{wt} \% \mathrm{Zn}$. These results showed that $\mathrm{Zn}$ promoted the reduction of $\mathrm{Ru}$, which differs from that previously reported by $\mathrm{Hu}$ and $\mathrm{Chen} \mathrm{[6].} \mathrm{da-Silva} \mathrm{and} \mathrm{Cobo}$ [17] showed that the addition of $\mathrm{Fe}$ to $\mathrm{Ru} / \mathrm{TiO}{ }_{2}$ and $\mathrm{Ru} / \mathrm{SiO}_{2}$ catalysts favored the reduction of $\mathrm{RuO}_{2}$. This might be the result of higher dispersion of the $\mathrm{RuO}_{2}$ particles, induced by Fe. Fan et al. [4] also reported a better dispersion of $\mathrm{Ru}$ caused by a high content of cobalt in the $\mathrm{Ru}-\mathrm{Co}-\mathrm{B} / \mathrm{Al}_{2} \mathrm{O}_{3}$ catalyst. From the literature mentioned above, it is reasonable to presume that the lowering of reduction temperature of $\mathrm{Ru}$ resulted from the better dispersion caused by $\mathrm{Zn}$.

To determine $\mathrm{Ru}$ dispersion in $\mathrm{Ru}-\mathrm{Zn} / \mathrm{MCM}-41$ catalysts, CO chemisorption was carried out. The molar ratio of $\mathrm{CO} / \mathrm{Ru}$ of the catalysts was $0.475,0.398,0.354$, and 0.386 , respectively, with $\mathrm{Zn}$ content of $0,0.25 \mathrm{wt} \%, 0.64 \mathrm{wt} \%$, and $1 \mathrm{wt} \%$. Contrary to our assumption Ru dispersion decreases with the addition of $\mathrm{Zn}$, and this indicates that there must be other factors that favor the reduction of Ru species.

Figure 4 shows the $\mathrm{H}_{2}$-TPD profiles of $\mathrm{Ru}-\mathrm{Zn} / \mathrm{MCM}$ 41 catalysts with differing $\mathrm{Zn}$ contents, with all the profiles demonstrating two main peaks. One is in the range of $350 \mathrm{~K}-$ $500 \mathrm{~K}$ and the other is higher than $600 \mathrm{~K}$. This indicates two forms of hydrogenation active sites. With the addition of $\mathrm{Zn}$, the integrated area of the low-temperature peak decreased, while that of the high-temperature peak increased. This change represents changes in the number of the two forms of hydrogenation active sites. With increasing $\mathrm{Zn}$ content, the number of relative weak hydrogenation sites (WHS) decreases and that of the strong hydrogenation sites (SHS) increases on the surface of Ru-Zn/MCM-41 catalysts. Hu and Chen [6] have reported the desorption peak with $T_{m}$ 


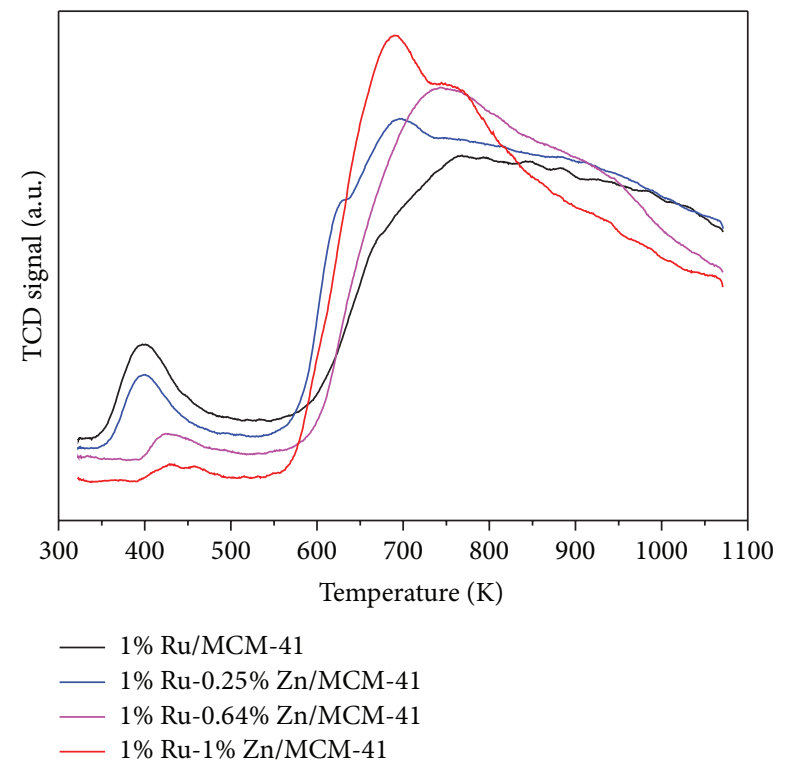

FIGURE 4: $\mathrm{H}_{2}$-TPD profiles of Ru-Zn/MCM-41 catalysts.

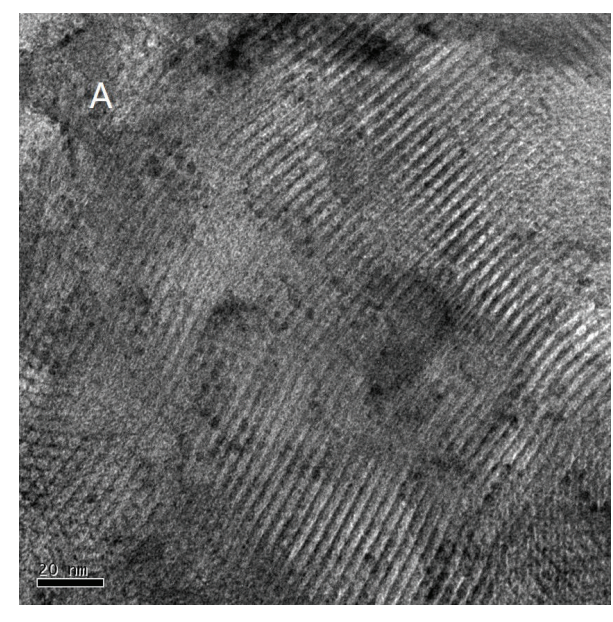

(a)

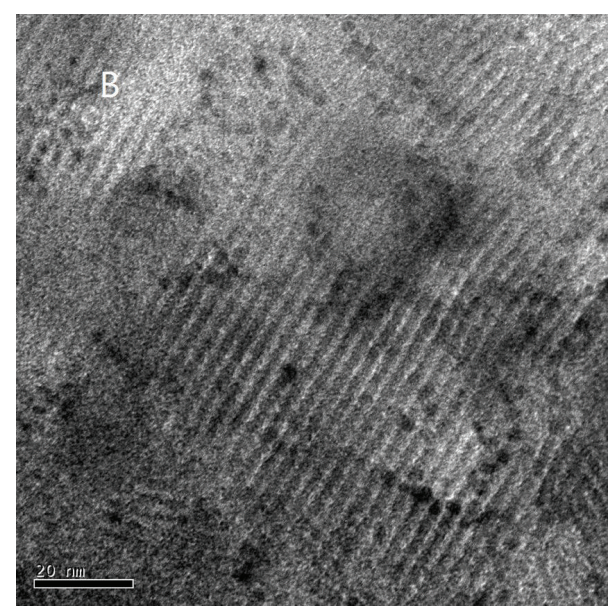

(b)

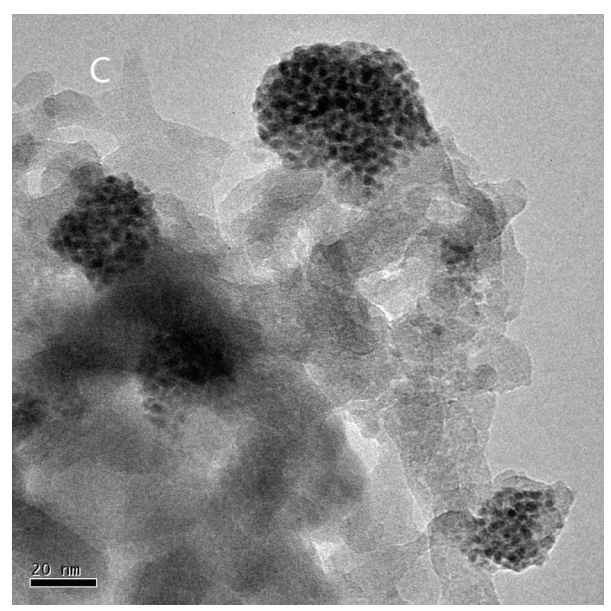

(c)

Figure 5: TEM photos of Ru-Zn/MCM-41 catalysts: (a) 1 wt\% Ru/MCM-41; (b) and (c) 1 wt\% Ru-1 wt\% Zn/MCM-41. 
about $423 \mathrm{~K}$ on $\mathrm{Ru} / \mathrm{SiO}_{2}$, which may be assigned to the $\mathrm{H}_{2}$ desorption from the $\mathrm{Ru}$ surface. Therefore, it is reasonable to conclude that the lower-temperature desorption peak is related to the $\mathrm{H}_{2}$ desorption from the free $\mathrm{Ru}$ surface, the WHS, and the latter is related to the $\mathrm{H}_{2}$ desorption from $\mathrm{Ru}$ surface affected by $\mathrm{Zn}$ and/or MCM-41, which is the SHS. In view of the catalytic activity results shown in Figure 1, it might be concluded that the number of WHS is correlated to benzene conversion, while the SHS is beneficial for cyclohexene hydrogenation. Therefore, with increasing Zn content, benzene hydrogenation activity decreases whilst cyclohexene hydrogenation activity increased.

To show more direct and convincing evidence for the existence of the novel Ru species, TEM photos were recorded. Figure 5(a) shows the TEM photo of Ru/MCM-41 and Figures 5(b) and 5(c) show the photos of Ru-Zn/MCM-41 catalyst with $\mathrm{Zn}$ content equaling $1 \mathrm{wt} \%$. In Figure 5(a), there are small $\mathrm{Ru}$ particles, with average size about $2.2 \mathrm{~nm}$ calculated from 25 particles, in the pores of MCM-41. When $\mathrm{Zn}$ is added to the catalyst, besides the small Ru particles shown in Figure 5(b), a novel kind of Ru conglomeration comes into being as shown in Figure 5(c). The conglomeration of Ru particles, with diameter about $30-50 \mathrm{~nm}$, was composed of small Ru particles less than $3 \mathrm{~nm}$. Its formation might be due to the effect of $\mathrm{Zn}$, because $\mathrm{Zn}$ can spread on the Ru particle surface as an overlayer [6] and then may act as a kind of adhesive to bind the Ru particles with each other. In addition, the slight decrease of Ru dispersion, caused by $\mathrm{Zn}$, indicates the loose combination of Ru particles in the conglomeration. In other words, there is space in the conglomeration to ensure the diffusion and adsorption of $\mathrm{CO}$.

The decrease of $\mathrm{Ru}$ reduction temperature could be explained by the loose conglomeration structure with confined space effect. During the reduction process, part of the $\mathrm{Ru}(\mathrm{III})$ was firstly reduced to $\mathrm{Ru}(0)$. Then $\mathrm{H}_{2}$ adsorbed dissociatively on the $\mathrm{Ru}(0)$ surface to form $\mathrm{H}$ atoms, which were more active. Furthermore, there was a high concentration of $\mathrm{H}$ atoms in the conglomeration. So, $\mathrm{Ru}(\mathrm{III})$ could be reduced at low temperature by the active $\mathrm{H}$ atoms.

\section{Conclusions}

With addition of $\mathrm{Zn}$ into Ru/MCM-41 catalysts, a kind of Ru particles conglomeration, with diameter about 30-50 nm, comes into being on the support. Its formation might be due to the fact that $\mathrm{Zn}$ can spread on the Ru particle surface as an overlayer and then may act as a kind of adhesive to bind the Ru particles with each other.

Ru-Zn/MCM-41 catalysts showed a decreased hydrogenation activity and cyclohexene selectivity with increasing $\mathrm{Zn}$ content. It can be attributed to the change of the amount of the hydrogenation sites affected by $\mathrm{Zn}$. The amount of weak hydrogenation sites, which can promote benzene conversion, decreases with the addition of $\mathrm{Zn}$. However, the amount of strong hydrogenation sites, which are beneficial for cyclohexene hydrogenation, changes in the reverse. And Ru species in the conglomeration were thought to be the strong hydrogenation sites.

\section{Conflict of Interests}

The authors declare that there is no conflict of interests regarding the publication of this paper.

\section{Acknowledgments}

This work was supported by the National Natural Science Foundation of China (nos. 21236001, 21176056, and 21106031), the Programme for 100 Excellent Talents in University of Hebei Province (II) (no. BR2-208), and the Natural Science Foundation of Hebei Province (no. B2015202228).

\section{References}

[1] H. Nagahara, M. Ono, M. Konishi, and Y. Fukuoka, "Partial hydrogenation of benzene to cyclohexene," Applied Surface Science, vol. 121-122, pp. 448-451, 1997.

[2] S.-C. Liu, Z.-Y. Liu, Z. Wang, Y.-M. Wu, and P. Yuan, "Characterization and study on performance of the $\mathrm{Ru}-\mathrm{La}-\mathrm{B} / \mathrm{ZrO}_{2}$ amorphous alloy catalysts for benzene selective hydrogenation to cyclohexene under pilot conditions," Chemical Engineering Journal, vol. 139, no. 1, pp. 157-164, 2008.

[3] W. Xue, Y. Song, Y. Wang, D. Wang, and F. Li, "Effect of hydrazine hydrate on the $\mathrm{Ru}-\mathrm{Zn} / \mathrm{SiO}_{2}$ catalysts performance for partial hydrogenation of benzene," Catalysis Communications, vol. 11, no. 1, pp. 29-33, 2009.

[4] G.-Y. Fan, W.-D. Jiang, J.-B. Wang, R.-X. Li, H. Chen, and X.J. Li, "Selective hydrogenation of benzene to cyclohexene over $\mathrm{RuCoB} / \gamma-\mathrm{Al}_{2} \mathrm{O}_{3}$ without additive," Catalysis Communications, vol. 10, no. 1, pp. 98-102, 2008.

[5] S. C. Liu, Z. Y. Liu, Z. Wang, S. H. Zhao, and Y. M. Wu, "A novel amorphous alloy $\mathrm{Ru}-\mathrm{La}-\mathrm{B} / \mathrm{ZrO}_{2}$ catalyst with high activity and selectivity for benzene selective hydrogenation," Applied Catalysis A: General, vol. 313, no. 1-2, pp. 49-57, 2006.

[6] S.-C. Hu and Y.-W. Chen, "Partial hydrogenation of benzene on $\mathrm{Ru}-\mathrm{Zn} / \mathrm{SiO}_{2}$ catalysts," Industrial \& Engineering Chemistry Research, vol. 40, no. 26, pp. 6099-6104, 2001.

[7] S. H. Xie, M. H. Qiao, H. X. Li, W. J. Wang, and J.-F. Deng, "A novel $\mathrm{Ru}-\mathrm{B} / \mathrm{SiO}_{2}$ amorphous catalyst used in benzene-selective hydrogenation," Applied Catalysis A: General, vol. 176, no. 1, pp. 129-134, 1999.

[8] Z. Liu, W.-L. Dai, B. Liu, and J.-F. Deng, "The effect of boron on selective benzene hydrogenation to cyclohexene over ruthenium boride powders," Journal of Catalysis, vol. 187, no. 1 , pp. 253-256, 1999.

[9] S.-C. Hu and Y.-W. Chen, "Partial hydrogenation of benzene to cyclohexene on ruthenium catalysts supported on $\mathrm{La}_{2} \mathrm{O}_{3}-\mathrm{ZnO}$ binary oxides," Industrial \& Engineering Chemistry Research, vol. 36, no. 12, pp. 5153-5159, 1997.

[10] V. Mazzieri, F. Coloma-Pascual, A. Arcoya, P. C. L’Argentière, and N. S. Fígoli, "XPS, FTIR and TPR characterization of $\mathrm{Ru} / \mathrm{Al}_{2} \mathrm{O}_{3}$ catalysts," Applied Surface Science, vol. 210, no. 3-4, pp. 222-230, 2003.

[11] J.-B. Ning, J. Xu, J. Liu, and F. Lu, "Selective hydrogenation of benzene to cyclohexene over colloidal ruthenium catalyst stabilized by silica," Catalysis Letters, vol. 109, no. 3-4, pp. 175180, 2006.

[12] V.-A. Mazzieri, P.-C. L’Argentière, F. Coloma-Pascual, and N.S. Fígoli, "Effect of chlorine on the properties of $\mathrm{Ru} / \mathrm{Al}_{2} \mathrm{O}_{3}$ ", 
Industrial \& Engineering Chemistry Research, vol. 42, no. 11, pp. 2269-2272, 2003.

[13] S.-C. Hu and Y.-W. Chen, "Effect of preparation on RuZn ultrafine catalysts in partial hydrogenation of benzene," Industrial \& Engineering Chemistry Research, vol. 40, no. 14, pp. 3127-3132, 2001.

[14] P. D. C. Zonetti, R. Landers, and A.-J.-G. Cobo, “Thermal treatment effects on the $\mathrm{Ru} / \mathrm{CeO}_{2}$ catalysts performance for partial hydrogenation of benzene," Applied Surface Science, vol. 254, no. 21, pp. 6849-6853, 2008.

[15] Y.-J. Zhao, J. Zhou, J.-G. Zhang, and S.-D. Wang, "Monolithic $\mathrm{Ru}$-based catalyst for selective hydrogenation of benzene to cyclohexene," Catalysis Communications, vol. 9, no. 3, pp. 459464, 2008.

[16] G.-Y. Fan, R.-X. Li, X.-J. Li, and H. Chen, "Effect of organic additives on partial hydrogenation of benzene," Catalysis Communications, vol. 9, no. 6, pp. 1394-1397, 2008.

[17] J.-W. da-Silva and A.-J.-G. Cobo, "The role of the titania and silica supports in $\mathrm{Ru}-\mathrm{Fe}$ catalysts to partial hydrogenation of benzene," Applied Catalysis A: General, vol. 252, no. 1, pp. 9-16, 2003.

[18] E. V. Spinacé and J. M. Vaz, "Liquid-phase hydrogenation of benzene to cyclohexene catalyzed by $\mathrm{Ru} / \mathrm{SiO}_{2}$ in the presence of water-organic mixtures," Catalysis Communications, vol. 4, no. 3, pp. 91-96, 2003.

[19] J. Bu, J.-L. Liu, X.-Y. Chen et al., "Ru/SBA-15 catalysts for partial hydrogenation of benzene to cyclohexene: tuning the $\mathrm{Ru}$ crystallite size by Ba," Catalysis Communications, vol. 9, no. 15, pp. 2612-2615, 2008.

[20] J.-L. Liu, L.-J. Zhu, Y. Pei et al., "Ce-promoted Ru/SBA-15 catalysts prepared by a 'two solvents' impregnation method for selective hydrogenation of benzene to cyclohexene," Applied Catalysis A: General, vol. 353, no. 2, pp. 282-287, 2009.

[21] P.-Q. Yuan, B.-Q. Wang, Y.-M. Ma, H.-M. He, Z.-M. Cheng, and W.-K. Yuan, "Partial hydrogenation of benzene over the metallic Zn modified Ru-based catalyst," Journal of Molecular Catalysis A: Chemical, vol. 309, no. 1-2, pp. 124-130, 2009.

[22] M.-F.-F. Rodrigues and A.-J.-G. Cobo, "Influence of the support nature and morphology on the performance of ruthenium catalysts for partial hydrogenation of benzene in liquid phase," Catalysis Today, vol. 149, no. 3-4, pp. 321-325, 2010.

[23] H.-Z. Liu, T. Jiang, B.-X. Han et al., "Highly selective benzene hydrogenation to cyclohexene over supported $\mathrm{Ru}$ catalyst without additives," Green Chemistry, vol. 13, no. 5, pp. 1106-1109, 2011.

[24] H.-Z. Liu, S.-G. Liang, W.-T. Wang, T. Jiang, and B.-X. Han, “The partial hydrogenation of benzene to cyclohexene over $\mathrm{Ru}-\mathrm{Cu}$ catalyst supported on ZnO," Journal of Molecular Catalysis A: Chemical, vol. 341, no. 1-2, pp. 35-41, 2011.

[25] H.-J. Sun, X.-D. Zhang, Z.-H. Chen et al., "Monolayer dispersed $\mathrm{Ru}-\mathrm{Zn}$ catalyst and its performance in the selective hydrogenation of benzene to cyclohexene," Chinese Journal of Catalysis, vol. 32, no. 2, pp. 224-230, 2011.

[26] H.-J. Sun, W. Guo, X.-L. Zhou, Z.-H. Chen, Z. Liu, and S. Liu, "Progress in $\mathrm{Ru}$-based amorphous alloy catalysts for selective hydrogenation of benzene to cyclohexene," Chinese Journal of Catalysis, vol. 32, no. 1, pp. 1-16, 2011.

[27] Y.-F. Qin, W. Xue, F. Li, Y.-J. Wang, and J.-F. Wei, "Preparation of $\mathrm{Ru}$-[bmim $] \mathrm{BF}_{4}$ and its catalytic performance for selective hydrogenation of benzene," Chinese Journal of Catalysis, vol. 32, no. 11, pp. 1727-1732, 2011.
[28] J. Liu, S.-M. He, C. Li et al., "Confined synthesis of ultrafine Ru$\mathrm{B}$ amorphous alloy and its catalytic behavior toward selective hydrogenation of benzene," Journal of Materials Chemistry A, vol. 2, no. 20, pp. 7570-7577, 2014.

[29] L.-Q. Yu, Q.-Q. Wang, C.-G. Liu, Y.-P. Zhang, and L.-Z. Hao, "Magnetically stabilized bed for selective hydrogenation of benzene," Chemical Engineering and Technology, vol. 37, no. 3, pp. 392-397, 2014.

[30] W. Xue, Q.-Q. Zhao, D.-D. Wang, W.-M. Du, and Y.-J. Wang, "Selective hydrogenation of benzene to cyclohexene over RU/MCM-41 catalysts," Acta Petrolei Sinica, vol. 25, supplement 2, pp. 120-124, 2009.

[31] F. Schwab, M. Lucas, and P. Claus, "Simple selective hydrogenation of benzene to cyclohexene in the presence of sodium dicyanamide," Green Chemistry, vol. 15, no. 3, pp. 646-649, 2013.

[32] W.-T. Wang, H.-T. Liu, T.-B. Wu et al., "Ru catalyst supported on bentonite for partial hydrogenation of benzene to cyclohexene," Journal of Molecular Catalysis A: Chemical, vol. 355, pp. 174-179, 2012.

[33] H. Liao, J. Zhang, P.-L. Liu, F. Hao, K. You, and H. Luo, "Hydrophilicity modification of MCM-41 with zirconia and supported ruthenium-lanthanum for benzene hydrogenation to cyclohexene," Synthesis and Reactivity in Inorganic, MetalOrganic and Nano-Metal Chemistry, vol. 43, no. 9, pp. 1206-1211, 2013.

[34] W. Xue, Y.-F. Qin, F. Li, Y.-J. Wang, and Z.-M. Wang, "Preparation of $\mathrm{Ru}$-[bmim $] \mathrm{BF}_{4}$ catalyst using $\mathrm{NaBH}_{4}$ as reducing agent and its performance in selective hydrogenation of benzene," Chinese Journal of Catalysis, vol. 33, no. 11-12, pp. 1913-1918, 2012.

[35] X.-H. Tan, G.-B. Zhou, R.-F. Dou et al., "Partial hydrogenation of benzene to cyclohexene over novel Ru-B/MoF catalysts," Acta Physico-Chimica Sinica, vol. 30, no. 5, pp. 932-942, 2014.

[36] C.-T. Kresge, M.-E. Leonowicz, W.-J. Roth, J.-C. Vartuli, and J. S. Beck, "Ordered mesoporous molecular sieves synthesized by a liquid-crystal template mechanism," Nature, vol. 359, no. 6397, pp. 710-712, 1992.

[37] H. Wang, Y. Yuan, L. Wei, K. Goh, D. Yu, and Y. Chen, "Catalysts for chirality selective synthesis of single-walled carbon nanotubes," Carbon, vol. 81, no. 1, pp. 1-19, 2015.

[38] D. Rath, S. Rana, and K.-M. Parida, "Organic aminefunctionalized silica-based mesoporous materials: an update of syntheses and catalytic applications," RSC Advances, vol. 4, no. 4, pp. 57111-57124, 2014.

[39] L.-T. Gibson, "Mesosilica materials and organic pollutant adsorption: part A removal from air," Chemical Society Reviews, vol. 43, no. 15, pp. 5163-5172, 2014.

[40] Z. Yuan and F. Liang, "Photoreactions in amphiphilic microreactors with 'soft' cavities: controlling product selectivity in solution," Current Organic Chemistry, vol. 18, no. 15, pp. 20162036, 2014

[41] R. Wojcieszak, S. Monteverdi, M. Mercy, I. Nowak, M. Ziolek, and M. M. Bettahar, "Nickel containing MCM-41 and AlMCM41 mesoporous molecular sieves: characteristics and activity in the hydrogenation of benzene," Applied Catalysis A: General, vol. 268, no. 1-2, pp. 241-253, 2004.

[42] N.-H.-H. Abu Bakar, M.-M. Bettahar, M. Abu Bakar, S. Monteverdi, and J. Ismail, "Low temperature activation of $\mathrm{Pt} / \mathrm{Ni}$ supported MCM-41 catalysts for hydrogenation of benzene," Journal of Molecular Catalysis A: Chemical, vol. 333, no. 1-2, pp. 11-19, 2010. 
[43] H.-X. Chen and Y. C. Wang, "Preparation of MCM-41 with high thermal stability and complementary textural porosity," Ceramics International, vol. 28, no. 5, pp. 541-547, 2002.

[44] P.-G.-J. Koopman, A.-P.-G. Kieboom, and H. van Bekkum, "Activation of ruthenium on silica hydrogenation catalysts," Reaction Kinetics and Catalysis Letters, vol. 8, no. 3, pp. 389-393, 1978.

[45] P.-G.-J. Koopman, A.-P.-G. Kieboom, and H. van Bekkum, "Characterization of ruthenium catalysts as studied by temperature programmed reduction," Journal of Catalysis, vol. 69, no. 1, pp. 172-179, 1981. 

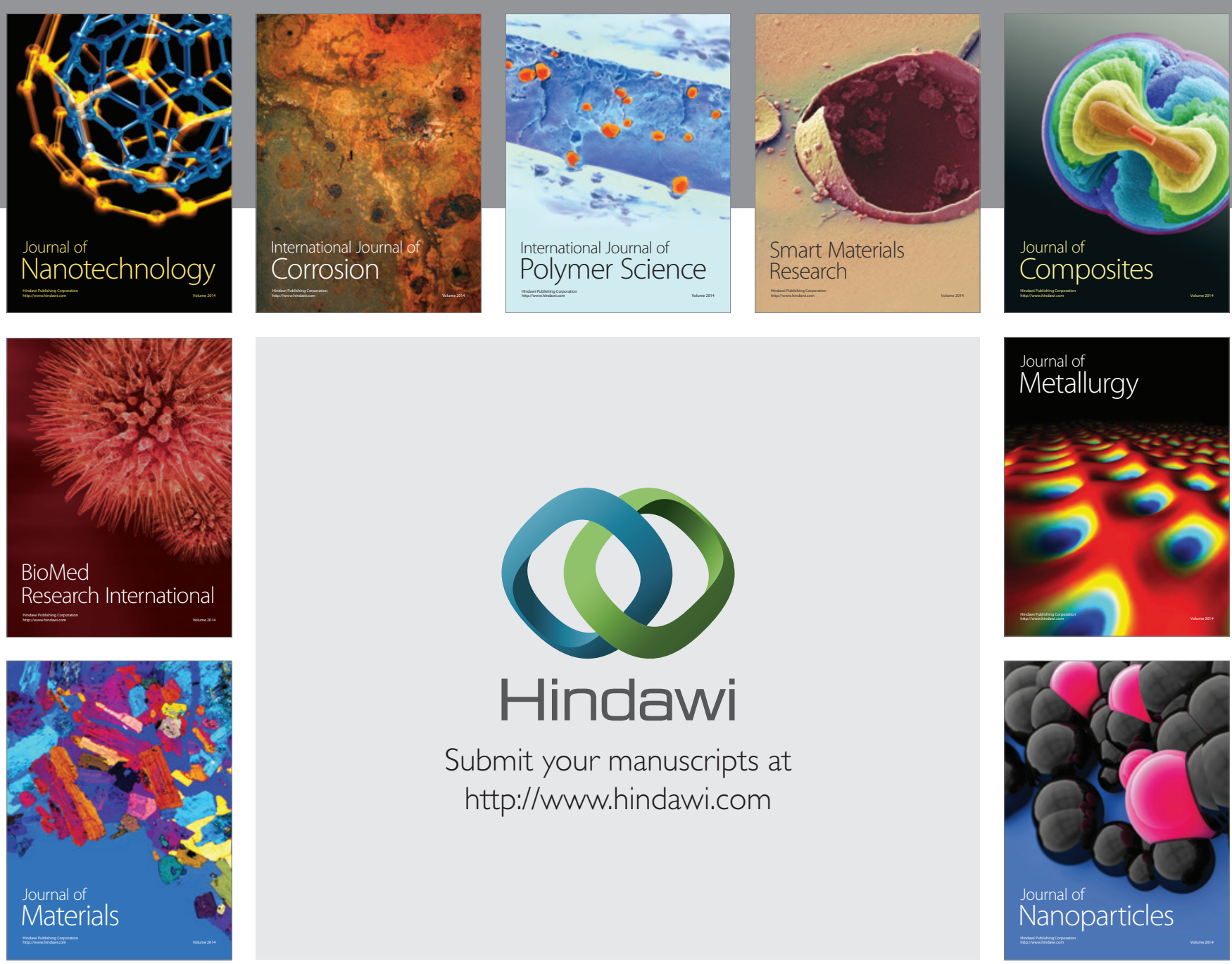

Submit your manuscripts at http://www.hindawi.com
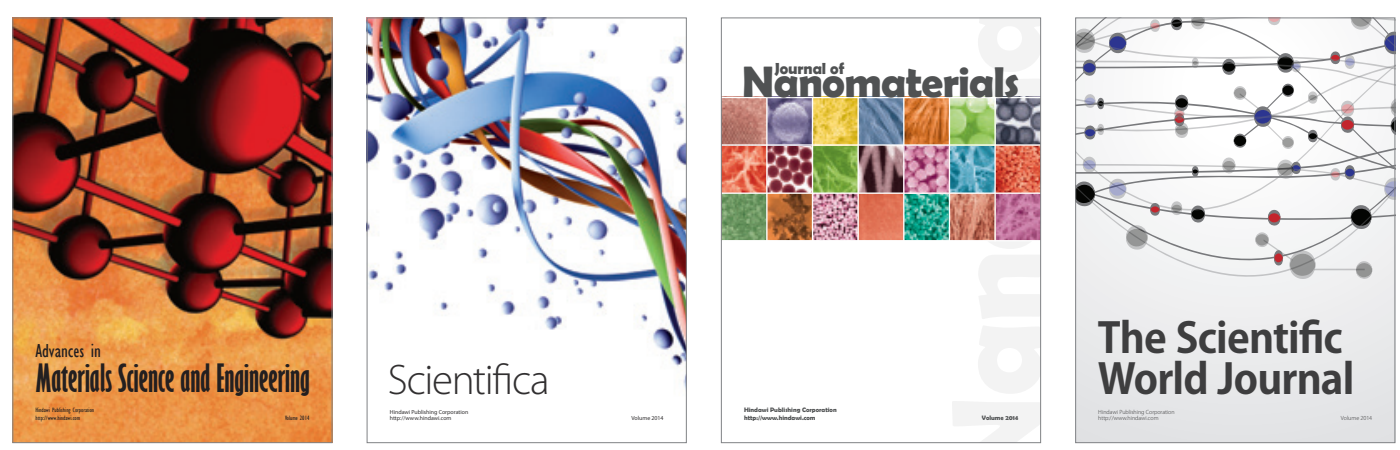

\section{The Scientific World Journal}
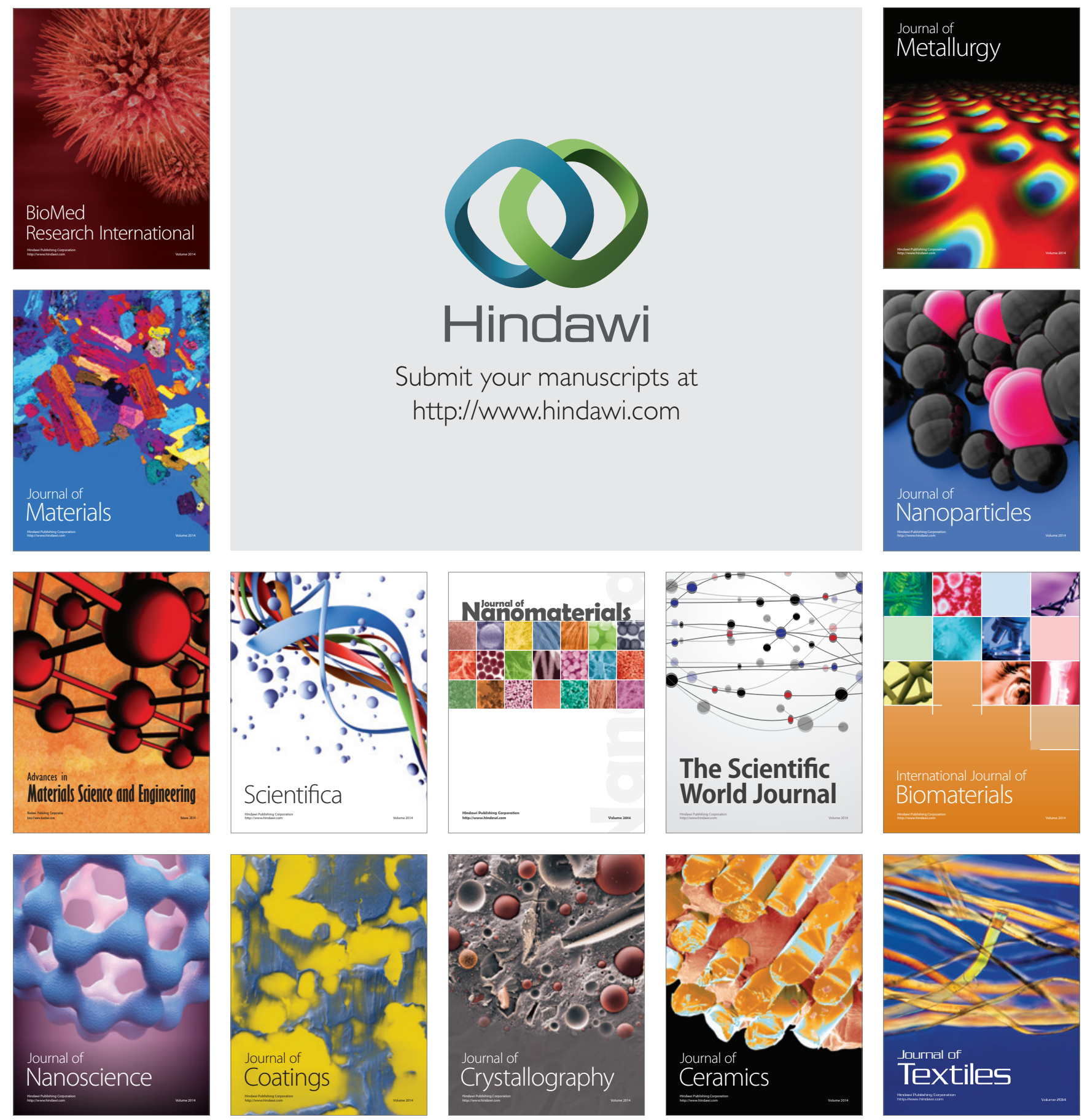